\title{
THE COMPARATIVE STUDY OF DIE CUSHIONING FORCE IN U- BENDING PROCESS USING FEA
}

\author{
Avinash $\mathbf{J}^{1}$, Hemanth. $\mathbf{R}^{2}$ \\ ${ }^{1} M$ tech Student, GTTC Mysore, \\ ${ }^{2}$ Lecturer, Dept. of Tool Engineering, GTTC Mysore
}

\begin{abstract}
This paper presents a study of the effect of the Die cushioning in the U-bending process. Different Die cushioning values are used to study their effect on distributions of stresses and strains in work piece. Two examples were analyzed one without Die cushion and another with Die cushion with Four values (10\%, 20\%,30\% and 40\% of bending load) were applied by Die cushioning on bottom of the workpiece.3D model of U-bending was used and analyzed by COSMOS.
\end{abstract}

Low carbon steel ( IS $2062 \mathrm{GrB}$ ) was chosen to carry out the simulation. The results show that the Die cushion force has an effect on the center displacement and distribution of strains and stresses in final product.

Keywords: U-bending, Die cushioning, FEA, Low carbon steel.

\section{INTRODUCTION}

Bending of sheet metal is one of the widely used in industrial process, especially in automobile and aircraft industries, sheet metal bending is one of the most widely applied sheet metal forming operation.

Bending is such a shaping process used commonly in various sheet metal industrial products. The sheet parts in these products and in the others are shaped using bending dies. According to the shape of the product, the bending is divided into the following.

1- Air bending.

2- U-bending

3- V-bending.

4- Roll bending.

5- Edge bending.

The accuracy and success of the bending process depends upon the operating parameters as well as, material properties, clearance, radius of the die and punch, friction condition etc.

\section{THE NATURE OF THE BENDING PROCESS}

Fig.1 Shows schematic representation of a simple sheet metal U-bending process. In general, the U-bending process passes into two steps, loading and unloading. In the loading step, a sheet metal is begins to bend into the die until the punch moves down completely. So that its shape is formed closely to the die shape. During this step, the work piece undergoes elastic-plastic deformation. Next, the unloading step is happened when the punch is removed. In this step dimension of the final product, particularly the bend radius angle becomes different from that of the product before unloading. This dimensional difference is called the elastic recovery phenomenon, and causes the springback.
In U-bending the work piece is also given its final shape by bottoming the punch. In this case, to prevent the bottom from bulging out during bending, (Fig2) a Die cushion is often used. During the bending process it already starts pressing against the bottom of the work piece.

When a Die cushion is applied in the bending process, flat bottom of the blank is subjected to an opposite force which tends to push the blank to up.

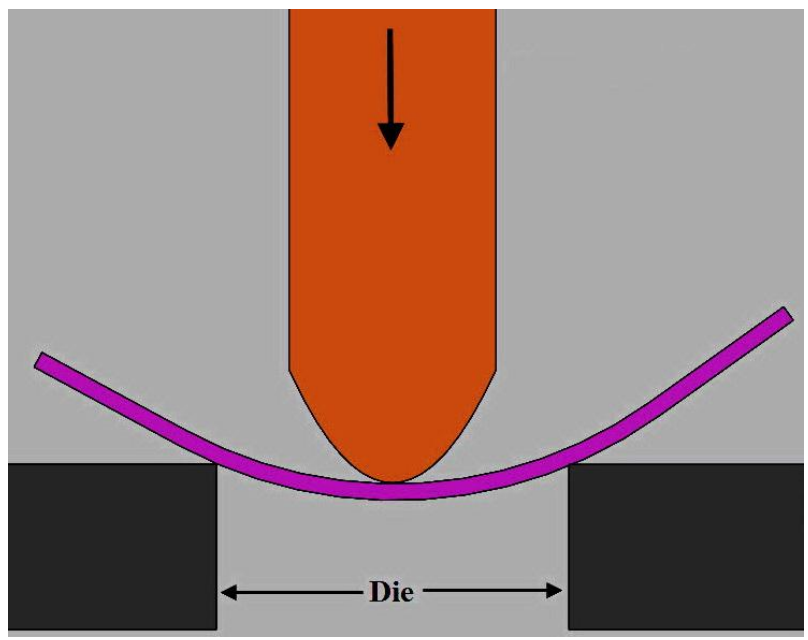

Fig 1 Simple sheet metal U-bending process

\section{DIE CUSHIONING}

The Die Cushioning is provided with either Die ejector system using springs or Multi point cushion system (MPC). Multi-point cushion (MPC) systems mostly consist of several individually programmable hydraulic cylinders, which apply the force directly to the blank holder. MPC systems are either integrated in the press (see Figure 3 ) or in 
the tooling. Thus they allow varying the BHF in location and during the stroke. This enables the manufacturer to better control the material flow into the die cavity. This prevents wrinkling, tearing and reduces thinning throughout the part.

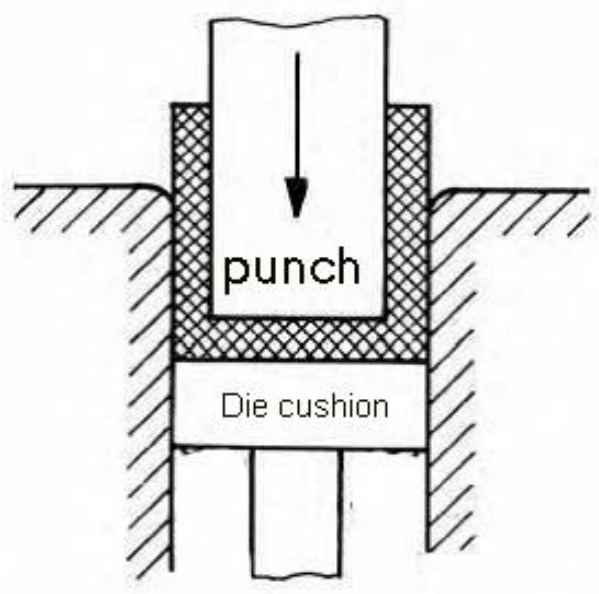

Fig 2 U-bending with Die cushion

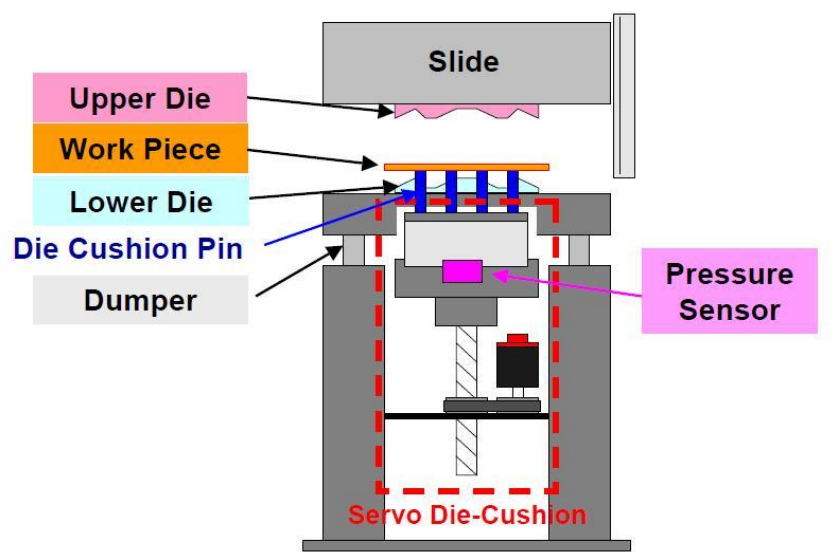

Fig 3 Die cushioning system integrated with Press.

\section{MATERIAL DETAILS}

\subsection{Work Piece (Blank)}

The material used in all simulation is low carbon steel (IS 2062 Gr B), where this type is used for stamping applications, such as, automobile bodies, engineering application and other applications. The material properties are taken as per the supplier standard. Table 1 shows the mechanical properties for Is $2062 \mathrm{Gr}$ B.

\subsection{Die}

D2 material is used for die. AISI D2 tool steel is one of the carbon steels alloyed with Mo, Cr, and V, is widely used for various dies and cutters for its high strength and wear resistance due to formation of chrome carbide in heat treatment.

\subsection{Bottom Plate}

Mild Steel is used for Bottom plate. Mild steel is the most versatile, least expensive and widely used engineering material which has found extensive application in various industries.

\subsection{Die Ejector}

D2 material is used for die ejector. AISI D2 tool steel is one of the carbon steels alloyed with Mo, Cr, and V, is widely used for various dies and cutters for its high strength and wear resistance due to formation of chrome carbide in heat treatment.

Table 1 Is 2062 Gr B material details

\begin{tabular}{|lcc|}
\hline Parameters & Units & Value \\
\hline Young's modulus (E) & $\mathrm{GPa}$ & 200 \\
\hline Tangent modulus (Et) & $\mathrm{GPa}$ & 0.5 \\
\hline Yield strength $(\sigma \mathrm{y})$ & $\mathrm{MPa}$ & 580 \\
\hline Poisson's ratio $(v)$ & & 0.3 \\
\hline Thickness $(\mathrm{t})$ & $\mathrm{mm}$ & 8 \\
\hline
\end{tabular}

\section{CALCULATION}

Bending Force,

$\mathrm{F}=\left[\left(0.67 \mathrm{LST}^{2}\right) / \mathrm{W}\right]$

$=[(0.67 \times 173 \times 410 \times 64) / 23]$

$=132.23 \mathrm{KN}$

Where,

$\mathrm{L}=$ Length of bent part in $\mathrm{mm}$.

$\mathrm{S}=$ ultimate tensile strength in $\mathrm{N} / \mathrm{mm} 2$

$\mathrm{T}=$ Thickness of blank in $\mathrm{mm}$

$\mathrm{W}=$ Span

Span,

$\mathrm{W}=\mathrm{RE}+\mathrm{C}+\mathrm{RP}$

$=8+8+7$

$=23 \mathrm{~mm}$

Where

$\mathrm{RE}=$ Edge Radius in $\mathrm{mm}$

$\mathrm{RP}=$ Punch radius in $\mathrm{mm}$

$\mathrm{C}=$ Die clearance in $\mathrm{mm}$

\section{NUMERICAL SIMULATION}

\section{FE Model}

For simulation the bending process, commercial FEA software COSMOS was used. 3D solid model was used for work piece (blank). The tool set (punch, Bottom plate and Die ejector) was modelled and assembled.

Static analysis has been carried out in which Bottom Plate is set as fixed geometry. Forming force is applied on the Work piece (blank). Finer mesh is created in the same software and is shown in Fig.4.

Geometric parameters of forming die are shown in table 2 . A Die Ejector is used to apply opposite force (Die 
cushioning) on the flat bottom of blank. The simulations were carried out with various value of Die cushioning. First case without Die cushion and another four cases have values $(10 \%, 20 \%, 30 \%$ and $40 \%$ of bending load).

Table 2 Tool Geometry data

\begin{tabular}{|ll|}
\hline Punch corner radius $(\mathrm{Rp}) \mathrm{mm}$ & 7 \\
\hline Die corner radius $(\mathrm{Rd}) \mathrm{mm}$ & 8 \\
\hline Punch-die clearance $(\mathrm{C}) \mathrm{mm}$ & 8 \\
\hline Workpiece thickness $(\mathrm{t}) \mathrm{mm}$ & 8 \\
\hline
\end{tabular}

\section{SIMULATION RESULTS.}

Two different condition simulation results and correspondence stress, strain and displacement photos of are illustrated below,

1. Without Die cushion,

2. With die cushion force i.e, $40 \%$ of forming force has been applied.

Other three conditions, i.e, $10 \%, 20 \%, 30 \%$, results are tabulated in the Table 3 .

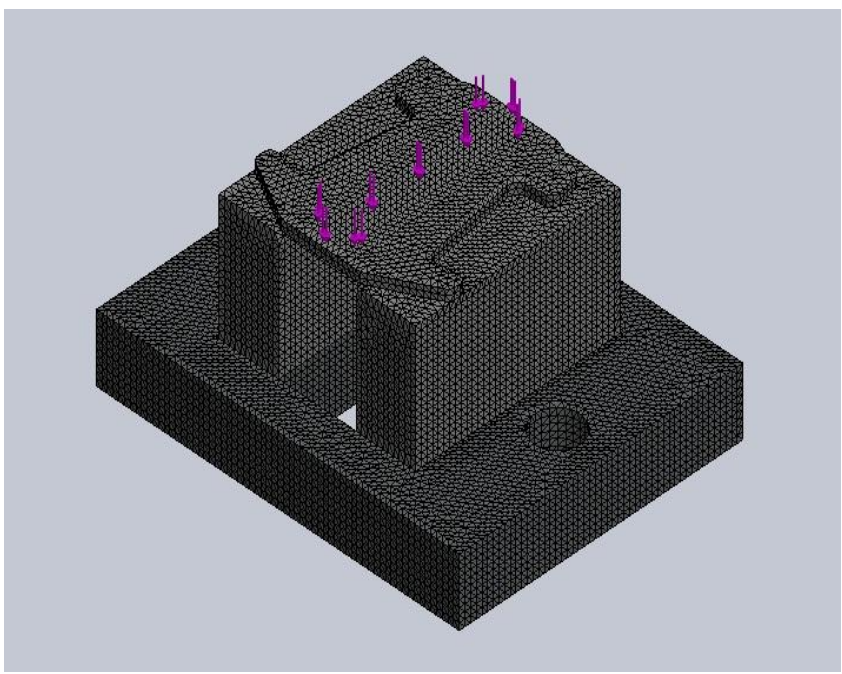

Fig.4 Fine mesh

Table 3 Result Table

\begin{tabular}{|l|l|l|}
\hline & $\begin{array}{l}\text { Stress in } \\
\mathrm{N} / \mathrm{mm}^{2}\end{array}$ & $\begin{array}{l}\text { Displacement } \\
\text { in mm }\end{array}$ \\
\hline Without Die cushion & 561.3 & 0.343 \\
\hline With Die cushion (10\%) & 164.1 & 0.047 \\
\hline With Die cushion (20\%) & 146.2 & 0.042 \\
\hline With Die cushion (30\%) & 128.3 & 0.037 \\
\hline With Die cushion (40\%) & 110.4 & 0.032 \\
\hline
\end{tabular}

\subsection{Without Die Cushion}

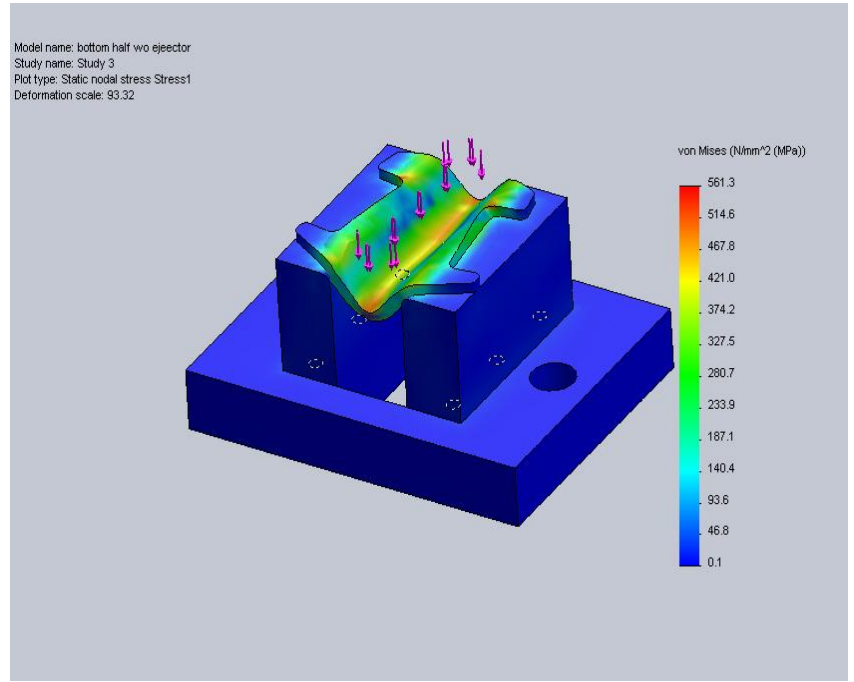

Fig 5 Stress distribution

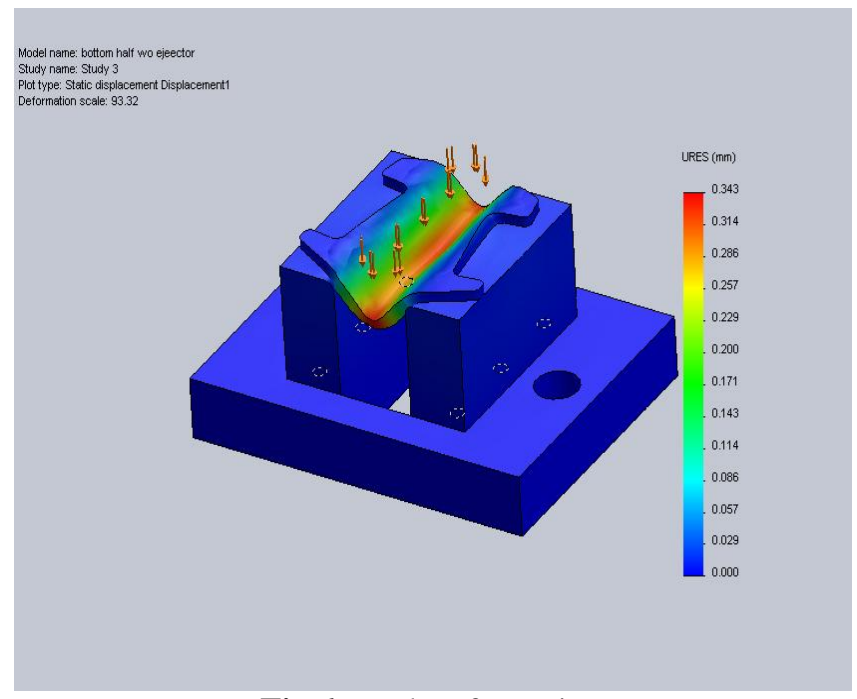

Fig 6 Total Deformation

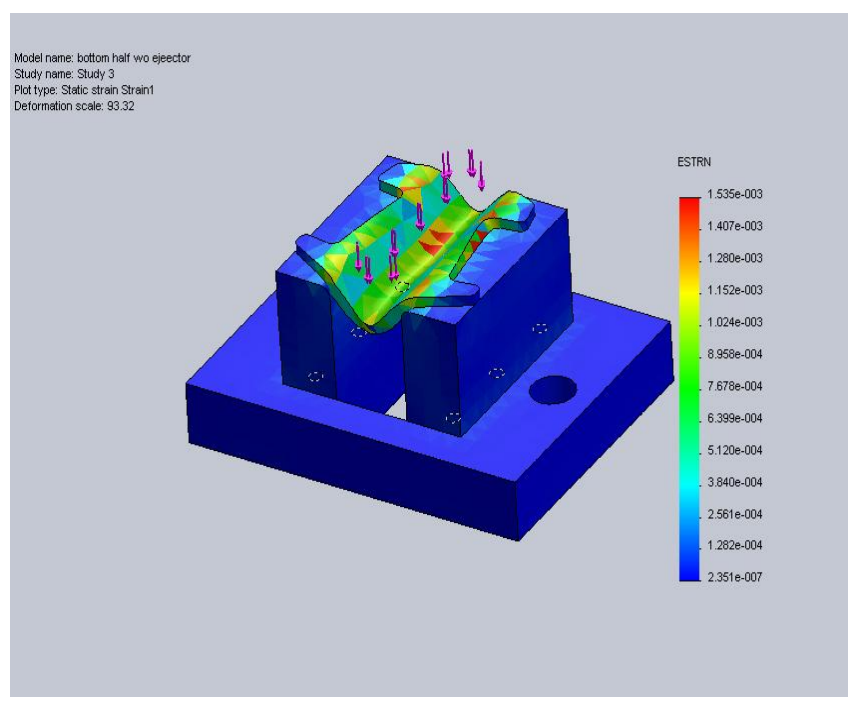

Fig 7 Strain 


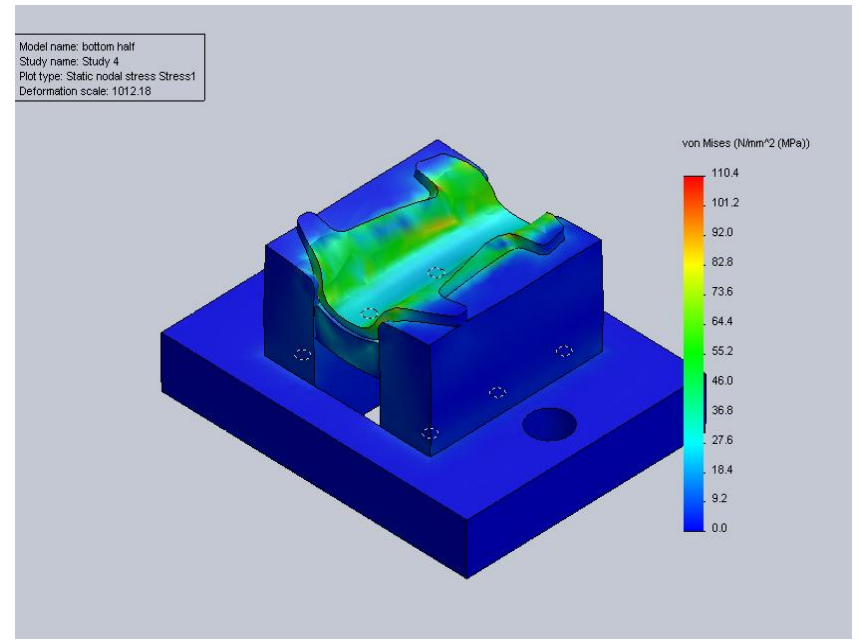

Fig8. Stress distribution

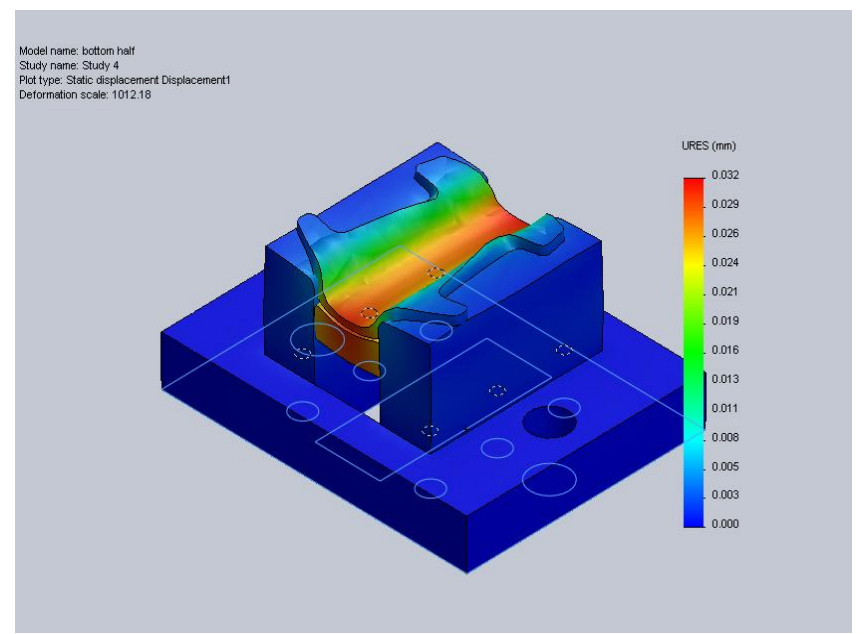

Fig 9 Total Deformation

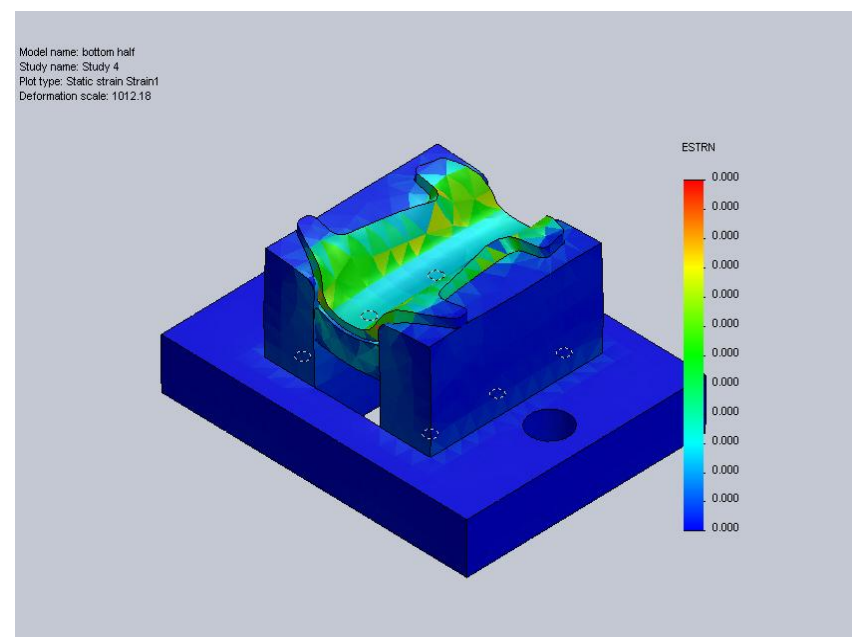

Fig 10 Strain

\section{CONCLUSIONS}

Detail study has been carried out on U-bending with die cushion and without die cushion. Correspondence analysis results are compared. The main conclusions, which can be deduced from the present work, can be summarized as follows:

1. Using of die cushioning has the effect on flatness in
U-bending.

2. Without die cushion more stresses are acting on the component which is almost equal to yield stress in some areas, which causes the failure of component.

3. By having $10 \%$ of die cushioning force, total displacement can be reduced significantly.

4. Increase in Die cushion force will reduces the stress acting on the component

\section{REFERENCES}

[1] Zafer Tekiner, An experimental study on the examination of spring back of sheet metals with several thicknesses and properties in bending dies, J. Mater. Process. Technol. vol.145, pp 109-117, (2004).

[2] R.H. Wagoner, J.L. Chenot, Metal Forming Analysis, John Willy \& Sons Inc., 1997.

[3] W.M.Chan, H.I.Chew, H.P.Lee, B.T.Cheok, Finite element analysis of Spring-back of V-bending sheet metal forming processes, J. Mater. Process. Technol. vol.172, pp 35-41, (2006).

[4] N.B.Suresh, A Lerner's guide to Press Tools, published by Pannaga international academy, fourth edition [2010].

[5] G.R.Nagpal, Tool Engineering and Design, Khanna Publishers.

[6] TOOL DESIGN DATA BOOK, directorate of technical education government of tamilnadu.

[7] GT\&TC Standard Data Hand Book.

[8] Prakash H.Joshi, Press Tool:Design \& Construction, Wheeler Publishing.

[9] Jutz-Scharkus, Westermann Tables, Revised second edition, new age international $(\mathrm{P})$ limited, publisher [2006] [1996]

[10] David A.Smith, Die Design Handbook, SMESociety of manufacturing engineers, Third Edition[1990]

\section{BIOGRAPHIE}

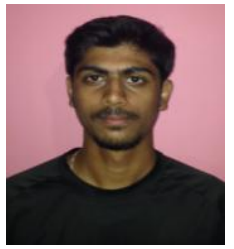

I am Avinash J, Doing M.Tech (Tool Engineering) in Government Tool Room and Training Centre, Mysore. Currently doing our final semester project work on Press Tool Design 